\title{
ADULET: AN INNOVATIVE COMMUNITY OF PRACTICE FOR HIGHER EDUCATION
}

\author{
Isabel Chumbo ${ }^{1}$, Vítor Gonçalves ${ }^{2}$, Elisabete Mendes Silva ${ }^{3}$, Maria Raquel \\ Patrício ${ }^{2}$ \\ ${ }^{1}$ Instituto Politécnico de Bragança (PORTUGAL) \\ ${ }^{2}$ Research Center in Basic Education, Instituto Politécnico de Bragança (PORTUGAL) \\ ${ }^{3}$ Instituto Politécnico de Bragança, CEAUL, Faculdade de Letras da Universidade de Lisboa, \\ (PORTUGAL)
}

\begin{abstract}
Higher education lecturers are currently overwhelmed with the idea of changing from the old paradigm, in which teaching and learning happened through a teacher-centred perspective, to a student centred approach, currently a more widely accepted new teaching standpoint, which lecturers are eager to transform into a vivid and motivating experience, by exploring various alternatives. The pressure to do so while resorting to several technological tools is enormous. The use of technological tools available to every student, namely smartphones, social networks, new platforms and other devices do not suffice anymore. Teachers and lecturers seek to go beyond the obvious tools and search for a way to combine these technologies and the new pedagogical approach in order to provide a more profound meaning to the teaching and learning process. AduLeT - Advanced Use of Learning Technologies in higher education - is a European project involving seven different institutions, which aims at improving the teaching quality of lecturers by enhancing their skills concerning the use of technologies in an advanced way, through a Community of Practice (CoP) where methods and tools are intertwined, thus envisaging a common outcome: sharing ready-made solutions which have been tested in a higher education context to solve an educational problem. The aims of this contribution are as follows: 1. to describe the project in the given context; 2 . to explain the different stages and methodology towards the design of the CoP; 3 . to provide insight about the CoP itself; 4 . To clarify how higher education teachers can use the CoP in their daily educational routine. The CoP is made available through a platform, currently correcting some functionalities in the evaluating stage with potential end users, which consists of an application developed with an author programming tool that allows getting flexible, visual, easy and logic navigation and interaction. The platform has been developed to provide users with a valuable experience to facilitate lecturers' understanding and usability. Our experience shows that a CoP could facilitate the adaptation process and allow a faster and more effective transferability of teaching innovations among different countries as well as among lecturers and universities at an international level. Currently the CoP already contains methods from different fields of knowledge and a variety of tools which can allow a lecturer to choose from, in order to include them in their lectures and seminars as to obtain a better interaction from the student's side and also to create a more motivated approach on a daily basis.
\end{abstract}

Keywords: AduLeT, Innovation, Community of Practice, methods, tools, higher education.

\section{INTRODUCTION}

Higher education lecturers are nowadays overwhelmed with the idea of having to change their teaching practice into an experience filled with motivation where technology is displayed as a fundamental means to obtain learning results.

This perspective has gathered momentum since the last two decades and with a stronger emphasis after the Bologna reform, has originated the need for a technological approach based on solid pedagogical foundations. Students have ready and fast access to tools such as smartphones, social networks, new platforms and other devices. Nevertheless, teachers and lecturers seek to go beyond these obvious tools and search for a way to combine these technologies and the pedagogical approach in order to provide a more profound meaning to the teaching and learning process. This is where the project AduLeT - Advanced Use of Learning Technologies in Higher Education finds it innovation.

A huge diversity of educational technologies is backed by literature discussing its utility and need in higher education [1] [2]. Studies confirm that current technology developments enable more integrated 
learning support for the learner's context, thus leading to more efficient and effective learning. This represents the ultimate aim of lecturers in higher education.

In many higher education institutions Learning Management Systems (LMS) are the main tool to further develop interactive and technology-based teaching and learning. However, this is neither always the case nor enough. Some teachers lack the knowledge or training to actively use LMS in their complete potentialities, resorting to these systems instead of others because they have an institutionally imposed role in technology based education [3] [4].

The AduLeT project addresses not only these constraints, but also proposes solutions to overcome them mainly through the facilitation of technology enhanced learning (TEL) tools and a set of methods, made available, after real-life implementation, through a platform whose main goal is to share best practices among higher education lecturers. The main objective that sustains this three year long project is the development of guidelines based on best practices, which comprise technical, didactical, infrastructural and organizational aspects so that the advanced use of technologies in higher education is facilitated.

AduleT is built as a consortium of eight institutions from seven different countries, where each higher education institution contributes with five expert lecturers, who, in turn, have been working with several other lecturers from different fields of expertise in order to build the community of practice. These are chosen from lecturers, of all fields of study, who have already some experience in using technologies or little experience but a keen interest to use TEL in their everyday teaching. The overall aim is to improve the teaching quality of lecturers by developing their skills concerning the use of technologies in an advanced way.

The main outcome of the project - the Community of Practice - brings therefore a solution for all these issues. The way it has been created and its implementations will be discussed next.

\section{METHODOLOGY}

The implemented methodology to achieve the CoP is twofold. On the one hand, the five main outputs of the project are linked in order to reach that purpose; on the other hand, a large group of people are contributing to it directly.

The CoP is the result of different outcomes within the project and compiled in a platform already available at https://dev.adulet.eu. The final community of practice will be public in June 2019 and will be sustainable by itself. We will proceed to explain how these different outcomes exist and interact in order to build up the CoP.

The first output to contribute to the CoP are the TEL Teaching Methods, a standardized and structured template created, revised and updated by the consortium where methods or methodologies for advanced technological use are described. For the purpose of this project, the consortium agreed upon the definition of method as "a logical process through which knowledge is obtained. It is organised in a succession of logical steps or stages aiming at achieving predetermined goal(s). A teaching method comprises a set of methodologies, strategies and techniques, tools and learning activities".

The template is being filled in by all the national participants, providing different information. To start, a name or title for the method must be provided. Then the lecturer explains the method used in combination with a specific tool and in which field of studies. Until now over 40 methods have been identified and described

The next output in the project is TEL tools. To collect them another template was created by the consortium, where the category of the tool is mentioned as well as several indications on the level of required technical skills or equipment and in which environment the tool can be best developed. For the project's sake a tool is a "set of instruments, either technological or didactic, used to perform a particular task/activity".

The first and second outcome intertwine in such a way that a matrix of possible combinations is generated and can then facilitate a both pedagogical and technological approach to TEL teaching in higher education. This can be seen in figure 1 . 


\title{
Adulet
}

\author{
TEL User eXperiences TEL Problems TEL Teaching Methods TEL Tools Register Log in
}

\section{User eXperiences}

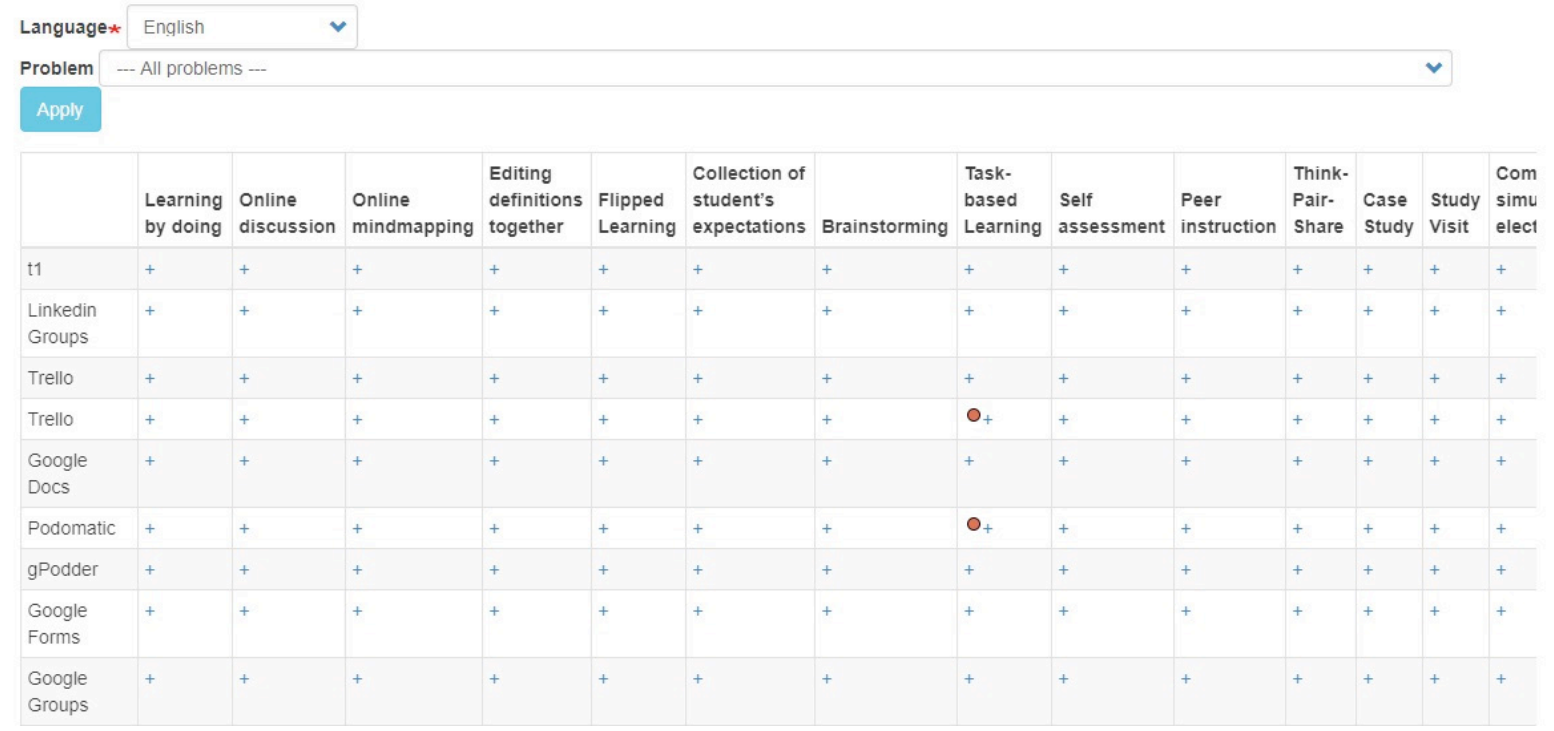

Figure 1. Example of TEL tools and TEL methods combination within the platform.

Case studies, which is the third outcome, embody a set of concepts on TEL technologies and their use in specific context, thus providing a relevant theoretical and experiential background to the lecturers and support to the platform.

The survey, which is the fourth output, deals with the existing barriers for the use of TEL at universities. It provides further insights into reasons why educators are hesitant to include TEL-based teaching methods into their daily teaching practice. The results obtained in the survey allow us to understand how lecturers in higher education feel when it comes to this topic. The survey was carried out with a sample of 104 participants, all of them lecturers in higher education. The methodology used to complete the survey was Group Concept Mapping, which allows both quantitative and qualitative approaches to collect and analyse a wide variety of data on the same subject, being able to reach a common view on an idea.

Overall, the participants have more than 20 years of experience in teaching, they come from different educational backgrounds as $47,1 \%$ of them come from the area of educational science, $14,7 \%$ from the area of social science and $20,6 \%$ from other non-specified areas. Only $17,6 \%$ of the participants come from the area of computer science and ICT. This means that the majority of the participants lack the level of expertise in using technological tools. The main result of the survey identifies six main barriers encountered by lecturers when faced with the use of TEL: lack of organization support, teachers' lack of knowledge and skills, lack of time, lack of hardware and software, students' lack of knowledge, skills and motivation, lack of reward and recognition.

The last output is the creation of the CoP itself through the implementation of a platform with a number of requirements. At first, a wiki-based tool was the main idea, but soon the consortium realized that this did not suffice to introduce all the diverse aspects and steps necessary to make the CoP a selfsustainable and facilitating tool for the future. After testing several solutions, like open source PHP framework Yii2, open source Apache HTTP Web server, and MySQL database engine, the final decision fell on using Drupal, which allows tailor-made solutions.

As explained, all mentioned outputs strongly relate to each other. Another methodology used towards the creation and implementation of the CoP was the 'Build the Community workshops'. These took 
place at all partner institutions in two different moments (in summer 2017 and spring 2018) and allowed the sharing, improvement and growth of the CoP through individual and group contribution.

The main goal of the first workshop was to identify the requirements of the CoP and the main purpose of the second was to test the CoP platform developed so far.

The first 'build the community' workshop focused on introducing the AduLeT project; presenting the Teaching Method template and TEL tool template to gather feedback and recommendations from the lecturers. Over 80 lecturers participated in this edition of the workshop in six universities. After this first round of workshops, the consortium agreed upon improvements for the templates.

The second version of the 'build the community' workshop was carried out after the implementation of the platform. As such, lecturers now had the opportunity to test the platform, to apprehend its several features and to identify further possibilities to be introduced. The workshop was mainly hands-on based aiming to obtain feedback from the participants about the CoP platform itself. Once again, while the participants were testing the CoP platform they identified problems and suggested improvements. This second edition of the workshop had over 100 participants.

Both workshops provided valuable contributions to the improvement of the CoP, which is noticeable in the online creation of over 40 teaching methods and tools online.

\section{RESULTS}

The main outcome of the project - the CoP platform - is already online, though not complete. At this stage it is ongoing work, which is still subject to improvements and recommendations of the partner institutions of the project.

Both TEL teaching methods and tools are introduced into the platform, though they are permanently being added. Over 40 are available online. The survey with 108 participants has been carried out and has produced six main constraints as being the most relevant ones preventing higher education lecturers of using more TEL tools in their classroom routine. The GCM method used revealed issues related to availability of ELearning tools, the need for technical and pedagogical support by organizations, insufficient time to learn ELearning tools and implement them into teaching practice, teachers' low self-efficacy in educational technology knowledge and skills, and lack of recognition for the efforts teachers have made. The several case studies concerning the use of technology enhanced learning also emphasize the aspects reached at through the survey.

Both 'build the community workshops' have produced enough suggestions to improve the platform and have provided material which the consortium believes is reliable and credible to be used in different higher education scenarios.

\section{CONCLUSIONS}

The AduLeT project wants to facilitate the advanced use of technologies in higher education through the implementation of a sustainable community of practice. As a conclusion, it can be said that all the outputs of the project have contributed to this accomplishment which will be made available in summer 2019, from the method and tool templates to the workshops.

Lecturers are feeling pressured to use TEL in their teaching contexts in order to reach a more active and engaged learning due to the students' lack of motivation and the urgent need to trigger about their attention and willingness into classes and unavoidably into learning. We believe that the project's outcomes flow into this direction, allowing lecturers to use the platform as a ready-made option for their teaching problems. Though we do not aim at being a final answer in the field of technology enhanced learning and teaching, we do propose several options for the lecturers. These are tested, validated and real-life context options which embed technology and pedagogy. This will allow lecturers to try a different approach in their teaching with a safety net which is facilitated by all the aspects contained in the platform.

\section{ACKNOWLEDGEMENTS}

AduLeT has been funded with the support of the European Commission and co-funded by the Erasmus+ Programme of the European Union. 


\section{REFERENCES}

[1] E. Duval; M. Sharples; R. Sutherland, Technology Enhanced Learning, Berlin: Springer, 2016.

[2] M. Specht; R. Klemke, "Enhancing Learning with technology", In D. Milosevic (Ed.), Proceedings of the fourth international conference on eLearning, pp. 37-45, 2013.

[3] E. Dahlstrom; C. Brooks; J. Bichsel, The Current Ecosystem of Learning Management Systems in Higher Education: Student, Faculty and IT Perspectives. Research report. Louisville: ECAR, 2014.

[4] P. A. Henning, "Stand der Technik und neueste Trends", HMD Praxis der Wirtschaftsinformatik, vol.52, no. 1, pp. 132-143. Berlin: Springer, 2015. 